\title{
Simulation of Indirect Field Oriented Control on 5- Phase Synchronous Reluctance Motor
}

\author{
Namariq Abdulameer Ameen*1, Ali Kadhim Abdulabbas², Habeeb Jaber Nekad ${ }^{3}$ \\ \{nam.almo79@gmail.com ${ }^{1}$, ali_univbasra75@yahoo.com ${ }^{2}$, hjn24177@gmail.com ${ }^{3}$ \} \\ Department of Electrical Engineering, University of Basrah, Iraq ${ }^{1{ }_{2}{ }_{3}}$
}

\begin{abstract}
Nowadays, multiphase ac machine drives are taken into consideration for several applications because they offer many advantages when in contrast with their three-phase equivalent. Therefore, in various applications, there is expanding in the achievement of the five-phase machine in electric drive systems. This paper uses mathematical modelling to demonstrate the dynamic simulation of a five-phase Synchronous Reluctance Motor SynRM driven by a five-phase current-controlled space vector PWM inverter. The theory of reference frame has been employed to get the transformation of five-phase SynRM voltage equations for removing the inductances angular dependency. The pulses for an inverter are created by applying the five-phase Space Vector Pulse Width Modulation (SVPWM) method. Then, for a fivephase SynRM, an indirect rotor flux-oriented vector control technique is constructed. Furthermore, the control block diagram is also presented in this paper with performance behaviour discussion under different load conditions and variance reference speed. The equivalent controllers are appropriately proposed to provide independent torque control. Finally, the obtained simulation results are typical and demonstrated by using Matlab/Simulink.
\end{abstract}

Keywords: Field-Oriented Control, Electric Drive Systems, Reluctance Torque, Synchronous Reluctance Motor.

\section{Introduction}

The synchronous reluctance motor (SynRM) has piqued the interest of many scientists and gained more attention as a possible substitution for an induction drive in recent decades, which is treated as a suitable choice for several variable-speed drive systems [1], [2], [3]. SynRM and induction motor (IM) are similar in stator construction, but its rotor has no field windings which results in reduced losses and higher efficiency [4]. Since SynRM is free of magnets, it is cheaper than permanent magnet motors [5]. SynRM has many advantages like it has a simple rugged structure, easy maintenance compared with induction motors, a reduced manufacturing cost, a moment of inertia is minor and the torque per unit volume is higher [2], [6]. The SynRMs are more durable than brushless (BL) motors and have lower rotor assembly costs [7]. The SynRM has the only rotor being salient, so it is structurally simpler than switched reluctance motor(SRM) with a doubly salient structure. Furthermore, from the standpoint of torque ripple, it is superior in SRM [8], [9]. There are some drawbacks in SynRM like power factor poorness and reduced torque density (slightly acceptable). These issues can be overcome by properly manipulating the design parameters of SynRM or by proposing a suitable control technique [4]. Besides, increasing the number of SynRM phases to reduce the undesired increase in the torque ripple is considered an effective way [10], [11]. 
In recent years, multiphase synchronous reluctance machines are treated as a perfect choice with the modern power electronics advancement, so the five-phase machine(in particular) has gotten a lot of coverage [12]. Commonly, high phase number drives are often favoured over three-phase drives for a variety of reasons. such as the high torque density, and improved efficiency, superior fault tolerance, amplitude lessening, torque pulsations, frequency rising, diminished harmonic currents in rotor, current per phase is reduced, phase voltage is nearly stable, DC link current harmonics are adequate, and dependability is improved. Hence, increasing the number of phases for an identical volume machine will enhance the torque per r.m.s ampere [2], [4], [13]. Furthermore, by injecting the third harmonic into a five-phase system, torque can be increased further without enlarging copper losses, in three-phase devices. However, incorporating the third harmonic to raise torque is not doable. SynRM model which includes the third harmonic and its influence on machine torque was presented in [3], [14].

Multi-phase projects for drive systems have recently been managed in specific demanding high trustworthiness, such as hybrid vehicles, ship propulsion, aircraft appliances, and applications requiring high power. Accordingly, the necessity of multiphase systems with n separate drive units is not inequitable for huge drives since various components are acquired in the present designs as in [15], [16].

In this paper, reference frame theory is used to model five-phase SynRM. Only the outer broad vectors are realized in Simulink of the five-phase current-controlled space vector pulse width modulation (SVPWM) technique using MATLAB simulation software. Besides that, the fundamental harmonic of spatial field is only employed to develop motor torque in executing a high-performance indirect rotor flux-based vector control technique. For SynRM drives, there are various current vector control techniques; the most widely used is the constant direct-axis current control technique, which is adopted in this paper. The direct-axis current reference value is maintained constant in this technique, while the quadrature-axis current is used to control motor torque. Accordingly, by regulating the $\mathrm{d}$ and $\mathrm{q}$-axis currents separately, the generated electromagnetic torque and rotor flux can be regulated. This paper is aimed to obtain the results by the current control technique, the electromagnetic torque and flux are fully decoupled. The speed for various loads, as well as different acceleration/deceleration and reverse modes, have been clarified.

The following sections of the paper are arranged as follows: Section II involves the system equations clarification and transformations needed for motor modelling. Section III demonstrates the five-phase space vector pulse width modulation(SVPWM) in operation. Section IV exhibits the implementation of the indirect flux-oriented vector control strategy by using MATLAB/SIMULINK. Section V and VI show the simulation implementation and simulation results, respectively. Finally, Section VII summarizes the paper with a brief conclusion.

\section{System Equations and Transformation}

Fig 1 illustrates a basic description model for a two-pole five-phase SynRM with concentrated winding in the stator and a salient pole rotor form created by the cut-out eliminated from around the rotor. The concentrated windings are the best choice in motor structure because the Distributed Windings stator (DW) outcomes in a high manufacturing cost resulted from the distributed winding difficulty [17]. 




Fig 1. Five-phase synchronous reluctance motor prototype.

Motor phases are moved apart by $72^{\circ}$ electrical degree [18]. The smallest air gap length that is shown in the figure is $g_{a}$, and the largest air gap length is denoted by $g_{b}$.Torque density is extremely influenced by the saliency ratio $\frac{g_{b}}{g_{a}}$. The rotor position $\theta$ is defined as the angle formed by the q-axis of the stator and the rotor. It is observed that the d-axis is phase-shifted from the q-axis by $90^{\circ}$.

The machine's dynamic behaviour can be described by parameter equations such as voltage, flux, and torque, which are time-varying variables. It is challenging to solve these differential equations, so variables with time-varying will be changed to time-invariant variables to decrease the motor voltage equations complexity caused by electric circuit relative motion. Iron saturation is neglected by assumption, and the fundamental component of air gap flux will only be kept in mind.

Generally, the following are the equations in the natural reference frame that describe the electrical characteristics of this machine in matrix form [2]:

Stator voltage equation:

$V_{s}=R_{s} I_{s}+p \lambda_{s}$

The equation for the Stator Flux Linkage is:

$\lambda_{s}=L_{s s} I_{s}$

Where $\mathrm{p}=\mathrm{d} / \mathrm{dt}$ and

$I_{S}=\left[\begin{array}{lllll}i_{a s} & i_{b s} & i_{c s} & i_{d s} & i_{e s}\end{array}\right]$

$V_{s}=\left[\begin{array}{lllll}v_{a s} & v_{b s} & v_{c s} & v_{d s} & v_{e s}\end{array}\right]$

$\lambda_{s}=\left[\begin{array}{lllll}\lambda_{a s} & \lambda_{b s} & \lambda_{c s} & \lambda_{d s} & \lambda_{e s}\end{array}\right]$ 
Also, $R_{s}=r_{s} I$ where $r_{s}$ is the resistance for every stator coil, considering that all coils are the same, and I am a $5 \times 5$ character matrix. In stator, $L_{s s}$ is a $5 \times 5$ symmetric inductance matrix with the pattern:

$L_{s s}=\left[\begin{array}{lllll}L_{a a} & L_{a b} & L_{a c} & L_{a d} & L_{a e} \\ L_{b a} & L_{b b} & L_{b c} & L_{b d} & L_{b e} \\ L_{c a} & L_{c b} & L_{c c} & L_{c d} & L_{c e} \\ L_{d a} & L_{d b} & L_{d c} & L_{d d} & L_{d e} \\ L_{e a} & L_{e b} & L_{e c} & L_{e d} & L_{e e}\end{array}\right]$

Because the inductance matrix $L_{s s}$ and the rotor position change together, the second expression of (1) be able to represent as

$\frac{d \lambda_{s}}{d t}=L_{S S} \frac{d I_{S}}{d t}+\frac{d L_{S S}}{d t} I_{s}$

By applying the chain rule, the equation's second term can be represented as

$\frac{d L_{S S}}{d t} I_{s}=\frac{d L_{S S}}{d \theta_{r m}} \frac{d \theta_{r m}}{d t} I_{s}$.

$\theta_{r m}$ is the rotor mechanical position, so the rotor mechanical speed is

$\omega_{r m}=\frac{d \theta_{r m}}{d t}$

So,

$\frac{d L_{S S}}{d t} I_{s}=\omega_{r m} \frac{d L_{S S}}{d \theta_{r m}} I_{S}$

Equation (7) can be written in the form

$\frac{d \lambda_{S}}{d t}=L_{s S} \frac{d I_{S}}{d t}+\omega_{r m} \frac{d L_{S S}}{d \theta_{r m}} I_{S}$

By substituting equation (11) into (1), the voltage equation is a natural frame of reference abcdethe system is giving by:

$V_{s}=R_{s} I_{s}+L_{s s} \frac{d I_{s}}{d t}+\omega_{r m} \frac{d L_{s s}}{d \theta_{r m}} I_{S}$

A five-phase synchronous reluctance machine's transient and steady-state performance can be expressed using the previously established equation set. As a result of the coupling degree between windings, these equations are slightly confusing for the reader, so it is suitable to signify the machine by the easiest equations set. There are renowned transformations that can make the equations easier if the space harmonics are disregarded. The salient structure of the rotor causes variation in the inductance matrix $L_{s s}$ concerning the rotor position.

A $5 \times 5$ transformation matrix $\mathrm{T}(\theta)$ is recommended for simplifying the windings inductance matrix and converting the variables from a stationary (a-b-c-d-e) reference frame to a rotating (d-q-X-y-n) reference frame to abstract the inductance reliance [2], [8]. 
That is $F_{\text {dqxyn }}=\mathrm{T}(\theta) F_{\text {abcde }}$

F may be either $\boldsymbol{V}_{\boldsymbol{s}}$ or $\boldsymbol{I}_{\boldsymbol{s}}$

Therefore, the transformation matrix is as follow:

$\mathrm{T}(\theta)=\frac{2}{5}\left[\begin{array}{ccccc}\cos \theta & \cos \left(\theta-\frac{2 \pi}{5}\right) & \cos \left(\theta-\frac{4 \pi}{5}\right) & \cos \left(\theta+\frac{4 \pi}{5}\right) & \cos \left(\theta+\frac{2 \pi}{5}\right) \\ \sin \theta & \sin \left(\theta-\frac{2 \pi}{5}\right) & \sin \left(\theta-\frac{4 \pi}{5}\right) & \sin \left(\theta+\frac{4 \pi}{5}\right) & \sin \left(\theta+\frac{2 \pi}{5}\right) \\ 1 & \cos \frac{2 \pi}{5} & \cos \frac{4 \pi}{5} & \cos \frac{4 \pi}{5} & \cos \frac{2 \pi}{5} \\ 0 & \sin \frac{2 \pi}{5} & \sin \frac{4 \pi}{5} & -\sin \frac{4 \pi}{5} & -\sin \frac{2 \pi}{5} \\ \frac{1}{\sqrt{2}} & \frac{1}{\sqrt{2}} & \frac{1}{\sqrt{2}} & \frac{1}{\sqrt{2}} & \frac{1}{\sqrt{2}}\end{array}\right]$

By employing the transformation in equation (14) to five-phase voltage matrix equation specified in (1), one can obtain the voltage equations denoted by the flux linkages in the synchronously rotating reference frame $(\mathrm{d}-\mathrm{g}-\mathrm{X}-\mathrm{y}-\mathrm{n})$ as given below:

$$
\begin{aligned}
& \boldsymbol{v}_{\boldsymbol{q s}}=\boldsymbol{r}_{\boldsymbol{s}} \boldsymbol{i}_{\boldsymbol{q} \boldsymbol{s}}+\boldsymbol{\omega} \lambda_{\boldsymbol{d s}}+\frac{\boldsymbol{d} \lambda_{q s}}{d t} \\
& v_{d s}=r_{s} i_{d s}-\omega \lambda_{q s}+\frac{d \lambda_{d s}}{d t} \\
& v_{x s}=r_{s} i_{x s}+\frac{d \lambda_{x s}}{d t} \\
& v_{y s}=r_{s} i_{y s}+\frac{d \lambda_{y s}}{d t} \\
& v_{n s}=r_{s} i_{n s}+\frac{d \lambda_{n s}}{d t}
\end{aligned}
$$

Fig 2 illustrates the five-phase reluctance machine equivalent circuits in balance operation. The $\mathrm{x}$-axis, $\mathrm{y}$-axis, and $\mathrm{n}$-axis equivalent circuits are all zero equivalent circuits that do not participate in torque development. The q-axis and d-axis equivalent circuits, on the other hand, are dependable for generating torque and magnetizing flux. Additionally, because of the decoupling activity between the q-axis and d-axis equivalent circuits, developing a control protocol to control this five-phase SynRM is not tricky [5]. 


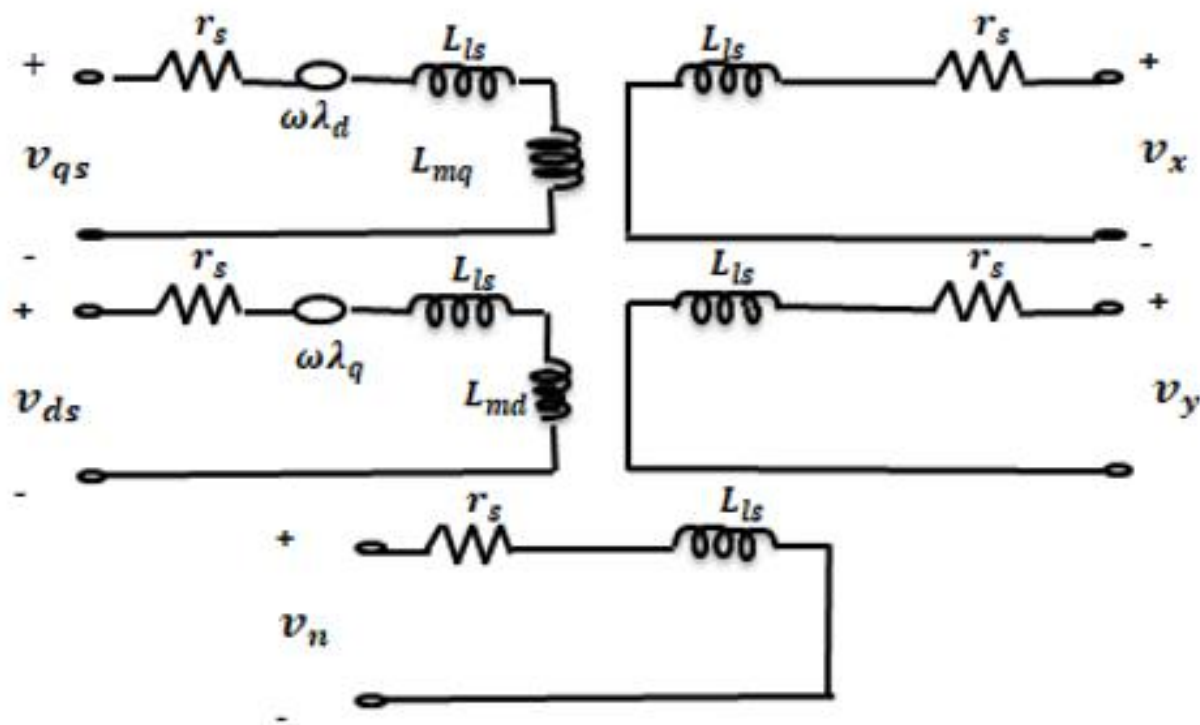

Fig 2. Five-phase SynRM equivalent circuit in the synchronous reference frame.

The electrical torque equation is attained from the magnetic co-energy $W_{c o}$ theory

$T_{e}=\left(\frac{\partial W_{c o}}{\partial \theta_{r}}\right)$

The stored magnetic energy is equal to the co-energy of a linear magnetic system.

$W_{c o}=\frac{1}{2} I_{s}^{t}\left[L_{s s}\right] I_{s}$

, and $T_{e}=\frac{P_{\text {in }}}{\omega} \frac{P}{2}$

$P_{\text {in }}=\frac{5}{2}\left(L_{m d}-L_{m q}\right) \omega i_{q s} i_{d s}$

Where $P_{\text {in }}$ represents the input power

$P$ represents the number of poles

$\omega_{m}$ represents the mechanical angular velocity

$T_{e}=\frac{5}{2} \frac{P}{2}\left(\lambda_{d s} i_{q s}-\lambda_{q s} i_{d s}\right)$

$=\frac{5}{2} \frac{P}{2}\left(L_{m d}-L_{m q}\right) i_{q s} i_{d s}$.

$T_{e}=\mathrm{J} \frac{d \omega_{m}}{d t}+\mathrm{B} \omega_{m}+T_{L}$

$\therefore \omega_{m}=\frac{1}{J} \int\left(T_{e}-\mathrm{B} \omega_{m}-T_{L}\right)$ 
Torque equation indicates that the torque is large when the saliency ratio $\frac{L_{d}}{L_{q}}$ is large, to enhance the torque density and improve the efficiency of synchronous reluctance motors, the saliency ratio must rise, and the difference $\left(L_{d}-L_{q}\right)$ must also be maximized in value. So far, such a ratio seems to have a physical limit with that structure, where the synchronous inductance is the maximum value of $L_{d}$ and the stator leakage inductance is $L_{q}$.

\section{Five-phase Space Vector Pulse Width Modulation Technique}

Fig 3 illustrates a five-phase Voltage Source Inverter (VSI) that uses the space vector pulsewidth modulation (SVPWM) method to create five-phase voltages for five-phase SynRM. In a five-phase inverter, there are five legs. Two power semiconductor switches (IGBTs) with antiparallel diodes are connected within each switch on each leg. The DC voltage source of the inverter is split into two equal parts, and the junction between the two sources is joined to the ground as in reference for load balancing. The gating signal (pulse generated for switches) is advanced or delayed by $72^{\circ}$. The inverter DC voltage source is converted into a controllable AC voltage source with changeable frequency and amplitude values [19].

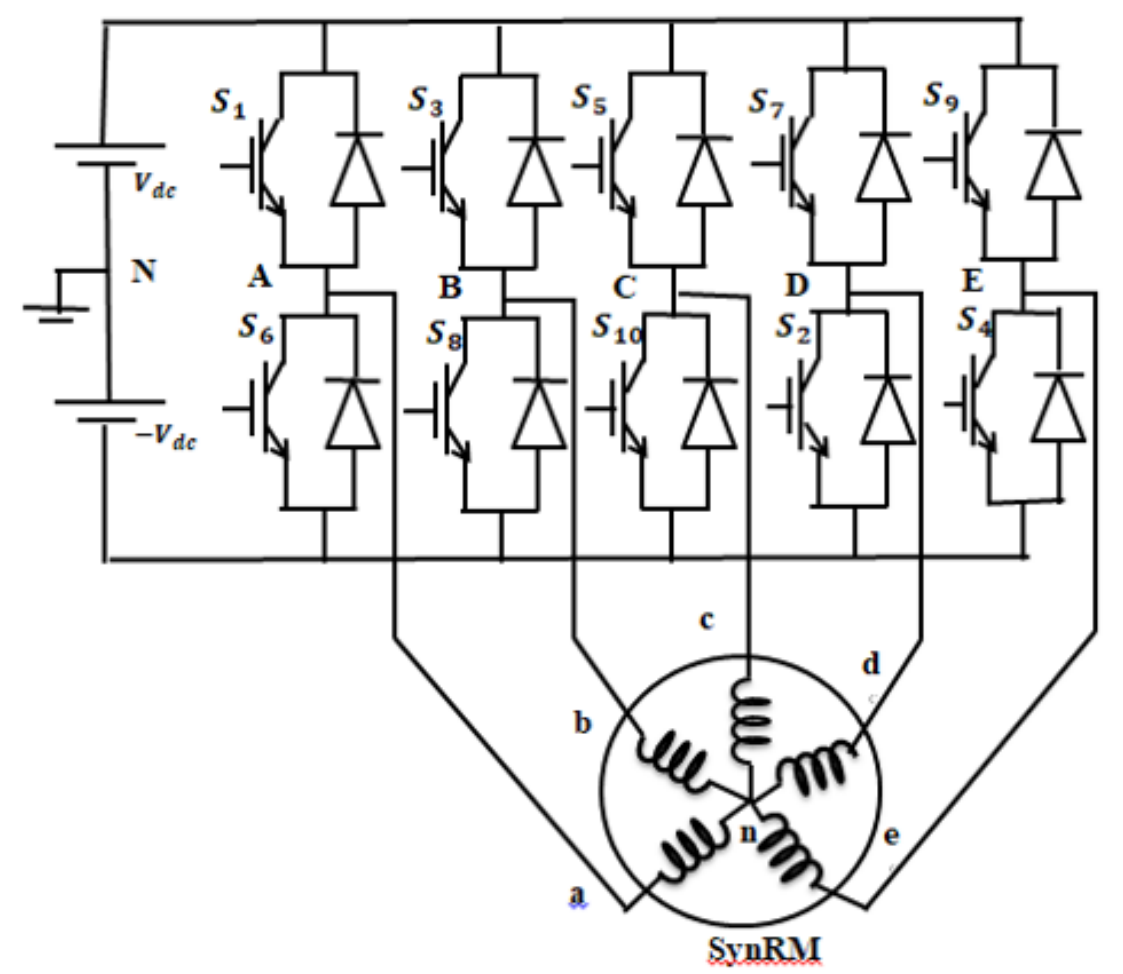

Fig 3. Five-phase Voltage Source Inverter. 


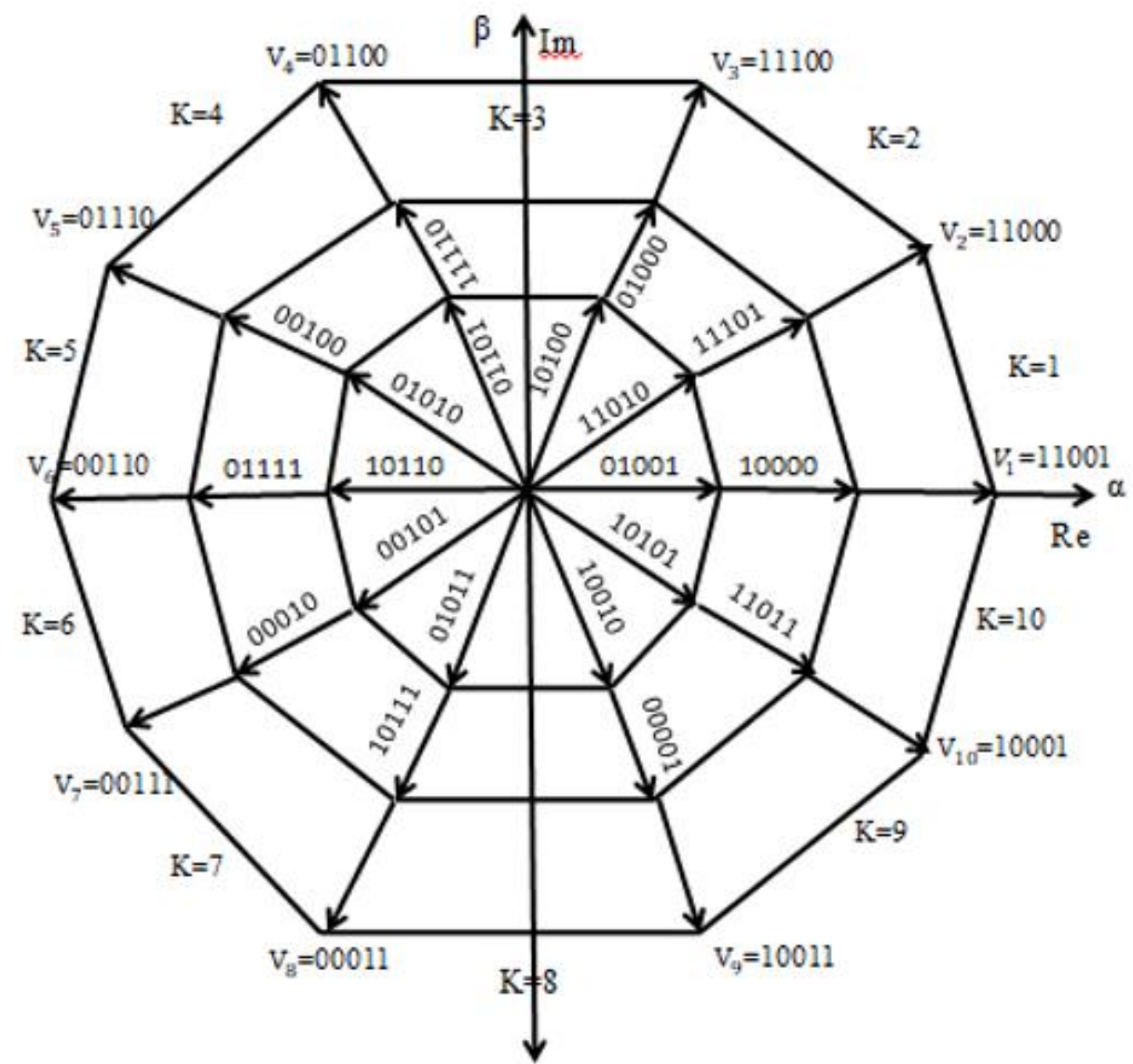

Fig 4. Switching vectors of all thirty-two states and voltage sectors.

Five-phase to neutral voltages transformation is as follows

$V_{a}=\left(\frac{4}{5}\right) V_{A}-\frac{1}{5}\left(V_{B}+V_{C}+V_{D}+V_{E}\right)$.

$V_{b}=\left(\frac{4}{5}\right) V_{B}-\frac{1}{5}\left(V_{A}+V_{C}+V_{D}+V_{E}\right)$.

$V_{C}=\left(\frac{4}{5}\right) V_{C}-\frac{1}{5}\left(V_{B}+V_{A}+V_{D}+V_{E}\right)$.

$V_{d}=\left(\frac{4}{5}\right) V_{D}-\frac{1}{5}\left(V_{A}+V_{B}+V_{C}+V_{E}\right)$.

$V_{e}=\left(\frac{4}{5}\right) V_{E}-\frac{1}{5}\left(V_{A}+V_{B}+V_{C}+V_{D}\right)$.

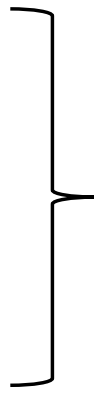

By using Clark's transformation, $V_{\propto}$ and $V_{\beta}$ is as follows.

$\left[\begin{array}{l}V_{\alpha} \\ V_{\beta}\end{array}\right]=\frac{2}{5}\left[\begin{array}{lllll}1 & \cos (2 \pi / 5) & \cos (4 \pi / 5) & \cos (4 \pi / 5) & \cos (2 \pi / 5) \\ 0 & \sin (2 \pi / 5) & \sin (4 \pi / 5) & -\sin (4 \pi / 5) & -\sin \left(\frac{2 \pi}{5}\right)\end{array}\right]\left[\begin{array}{c}V_{a} \\ V_{b} \\ V_{c} \\ V_{d} \\ V_{e}\end{array}\right]$ 
Then $\left|V_{\text {ref }}\right|$, and $\alpha$ can be determined as follows:

$\left|V_{\text {ref }}\right|=\sqrt{V_{\alpha}^{2}+V_{\beta}^{2}}$

$\alpha=\tan ^{-1}\left(\frac{V_{\beta}}{V_{\alpha}}\right)=\omega \mathrm{t}=2 \pi \mathrm{ft}$

Where $\mathrm{f}$ is the fundamental frequency.

There are thirty-two vectors that thirty of them are non-zero switching vectors. The remaining two vectors seem to be zero switching vectors. Fig 4 depicts the non-zero vectors. The apexes of the three decagons are equipped with all thirty non-zero vectors. These decagons are different in length of their sides where their amplitude ratio is $1: 1.618: 1.618^{2}$, starting from the least one to the largest one. Only one phase vector of the ten furthest vectors with the largest amplitudes will be switched from one vector in every two adjacent vectors. Therefore, these vectors are utilized to form five-phase currents, and these ten non-zero vectors shown in Fig 5 are the same as the six non-zero vectors in the three-phase inverters [20].

The constant switching frequency of SVPWM is a benefit. Accordingly, this technique is usually employed in three-phase systems, which are similarly developed for five-phase systems. If it is taken for one switching time interval $T_{S}$, the two non-zero vectors that are adjacent to the reference vectors $V_{\text {ref }}$ and the two zero vectors are selected. These vectors will conduct for their predetermined periods ensuring that the specific voltage follows the reference voltage. The first and second non-zero vectors conduction time in addition to the zero vectors are given in equations (26)-(28) [21].



Fig 5. Ten switching vectors of five-phase SVPWM. 
$T_{1=} \frac{\left|V_{r e f}\right| \sin \left(\frac{k \pi}{5}-\alpha\right)}{|V| \sin \left(\frac{\pi}{5}\right)} T_{S}$

$T_{2}=\frac{\left|V_{r e f}\right| \sin \left(\alpha-\frac{(k-1) \pi}{5}\right)}{|V| \sin \left(\frac{\pi}{5}\right)} T_{S}$

Where $\mathrm{k}=1,2 \ldots 10$ is the number of sectors that corresponds to the location of the reference vector.

, and

$T_{0}=T_{S}-T_{1}-T_{2}$

Where $\left|V_{\text {ref }}\right|$ is reference space vector, and $T_{s}$ is switching time which is equal to $\frac{1}{f_{s}}$.

Angle $\alpha$ represents the reference voltage vector angle and its range is between $(0,2 \pi)$.

In the next step, the switching period of every switching device is determined as shown in Fig 6. The total switching period $T_{s}$ is divided into seven parts with zero state vector adopted in the first and the last quarter for the half zero state vector time, while active state vectors are employed in the second and third portions for half of the whole time of their vector. This sequence will be repeated in the second half of the switching cycle [18].

When the reference vector is situated at $\mathrm{k}$ is 1 in the first sector as illustrated in Figure 5, for reducing total switching, the two non-zero vectors $V_{1}$ and $V_{2}$ are conducting with two zero vectors as shown below: in the first time interval, the vector $V_{0}(00000)$ is affected for the time $\frac{t_{0}}{2}$, then $\mathrm{A}$ and $\mathrm{B}$ will be switched on when $V_{2}(11000)$ is active at the period $T_{2}$. Next, E will be switched on, and the vector $V_{1}(11001)$ is active during $T_{1}$. In response to this, $\mathrm{C}$ and $\mathrm{D}$ will finally be switched on when $V_{31}(11111)$ is activated at the time instant $\frac{T_{0}}{2}$.For subsequent time interval which is a mirror to the previous one, the conducting succession will be $\bar{V}_{31}-\bar{V}_{1}-\bar{V}_{2}-\bar{V}_{0}$ for $\frac{T_{0}}{2}, T_{1}, T_{2}$ and $\frac{T_{0}}{2}$ correspondingly; thereafter, If the reference vector is already in the first sector, this arrangement would be maintained. Figure 6 depicts the entire switching pattern. Each stage is only switched once throughout each time interval, and each time interval starts from zero vector $\bar{V}_{0}$ and finishes in zero vector $\bar{V}_{0}$ at the end of the following time interval that results in minimized total switching losses.

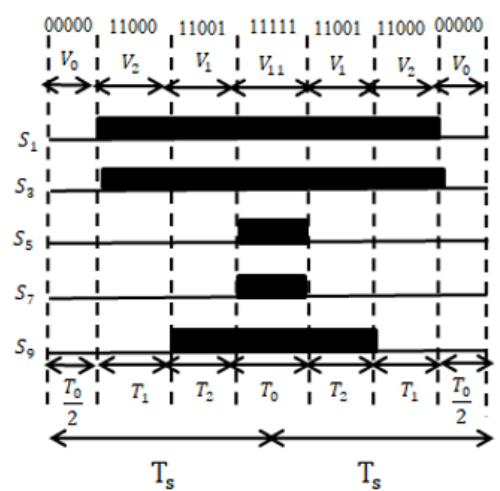

(a)

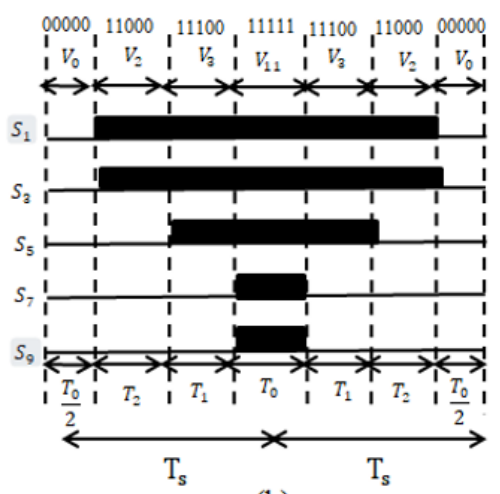

(b)

Fig 6. Five-Phase switching time interval, (a) sector-1, (b) sector-2. 
Fig 7 illustrates a Simulink model of the SVPWM inverter with a five-phase SynRM. Clark transformation was applied to transfer five-phase reference frame to $\alpha \beta$-reference frame $\left(v_{\alpha}\right.$ and $v_{\beta}$ ) which are utilized in the five-phase VSI's pulse generator block.

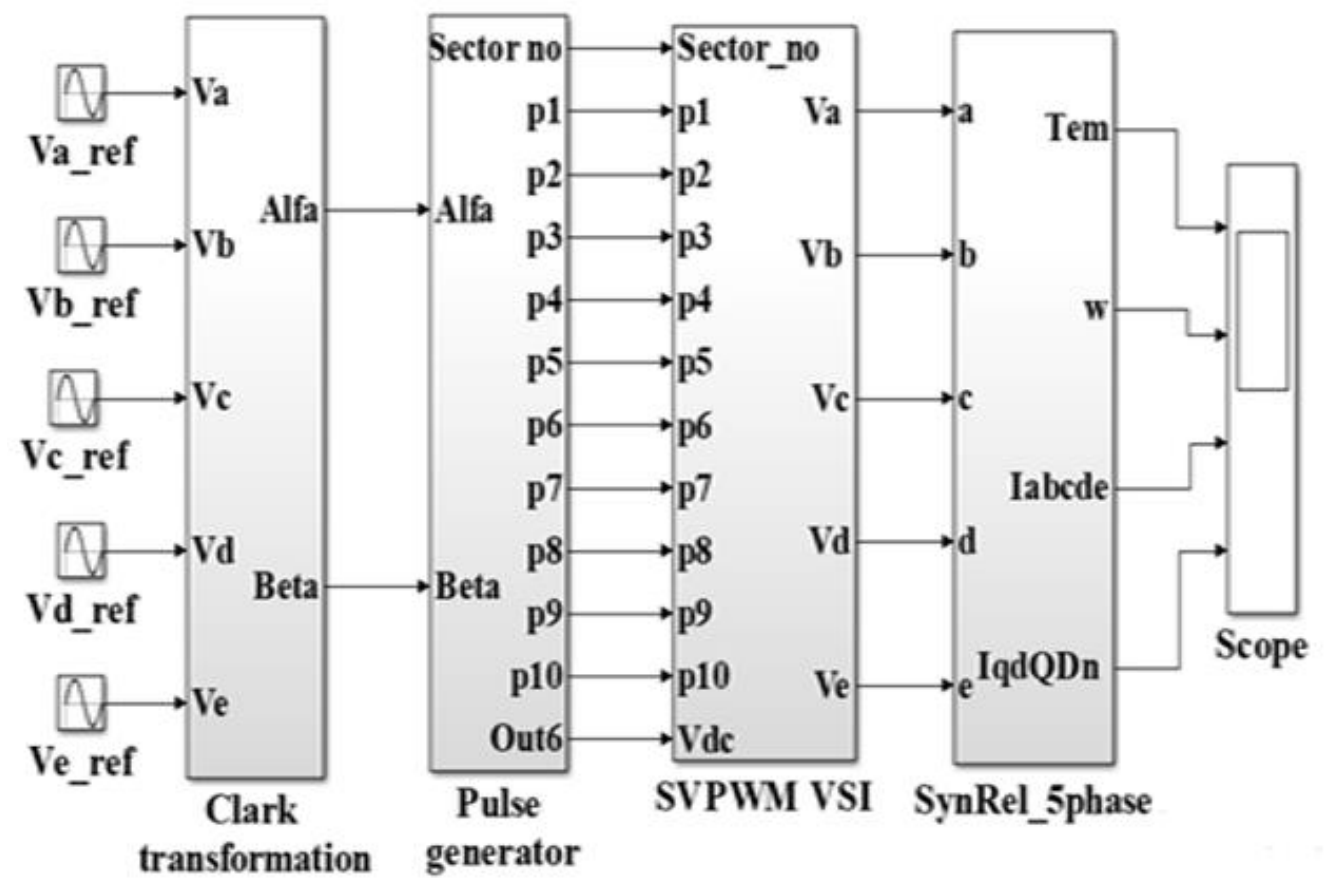

Fig 7. Simulink model of SVPWM Implementation on SynRM.

\section{Rotor Flux Field Oriented Vector Control}

Direct and indirect vector control methods are the two different types of vector control methods. Rotor flux-oriented vector control, stator flux-oriented vector control, and magnetizing flux-oriented vector control are the three types of indirect vector controls. The direct employment is dependent on the rotor, stator, or magnetizing flux linkage vector amplitude and location being directly measured or approximated. In comparison to direct methods, indirect methods are extremely reliant on system parameters. Scan coils tapped stator windings, or Hall-effect sensors aimed at flux sensing are used in traditional direct vector control algorithms. This will reveal any constraints imposed by the machine's structural and thermal environments. Since indirect control systems have less complicated hardware, they have increased overall efficiency at low speeds. The five-phase synchronous reluctance machine is regulated using a rotor-flux field-directed control approach, as shown below.

At steady state, the q-axis and d-axis voltage equations can be obtained from equations (15).

$V_{q s}=r_{s} i_{q s}+\omega \lambda_{d s}+\frac{d \lambda_{q s}}{d t}$ 
$V_{d s}=r_{s} i_{d s}-\omega \lambda_{q s}+\frac{d \lambda_{d s}}{d t}$

As shown in (19), the electromagnetic torque and q-axis current can be calculated:

$\therefore T_{e}=\frac{5}{2} \frac{P}{2}\left(\lambda_{d s} i_{q s}-\lambda_{q s} i_{d s}\right)$

Now, using rotor flux field-oriented technique, where $\lambda_{q s}=0$,

$i_{q s}=\frac{T_{e m}}{K_{T} \lambda_{d s}}$

Where, $K_{T}=\frac{p}{2} \frac{5}{2}\left(1-\frac{L_{q s}}{L_{d s}}\right)$

Only the reference quadrature axis current regulates the torque in this process, as shown in equation (32); the reference direct axis current is kept constant. The rotor flux field-oriented vector control of the five-phase synchronous reluctance motor is depicted in Fig 8, based on equations (29)-(32), where stator stationary axes represent $\alpha$ and $\beta$, and rotor synchronous rotating axes are $\mathrm{d}$ and $\mathrm{q}$. Fig 9 illustrates the block diagram of the control system of this paper using the five-phase transformation in (19) and five-phase current regulated PWM by specific switching pattern selection to trigger the five-phase inverter IGBTs. A speed PI controller is used in the control block scheme, with the speed error as its input and the reference torque as its output. By utilizing (32), the q-axis current can be determined whose error is an input to another current PI controller. The d-axis current error is the input to the second current PI controller. The d-axis and q-axis demand voltages can be determined using (29) and (30).

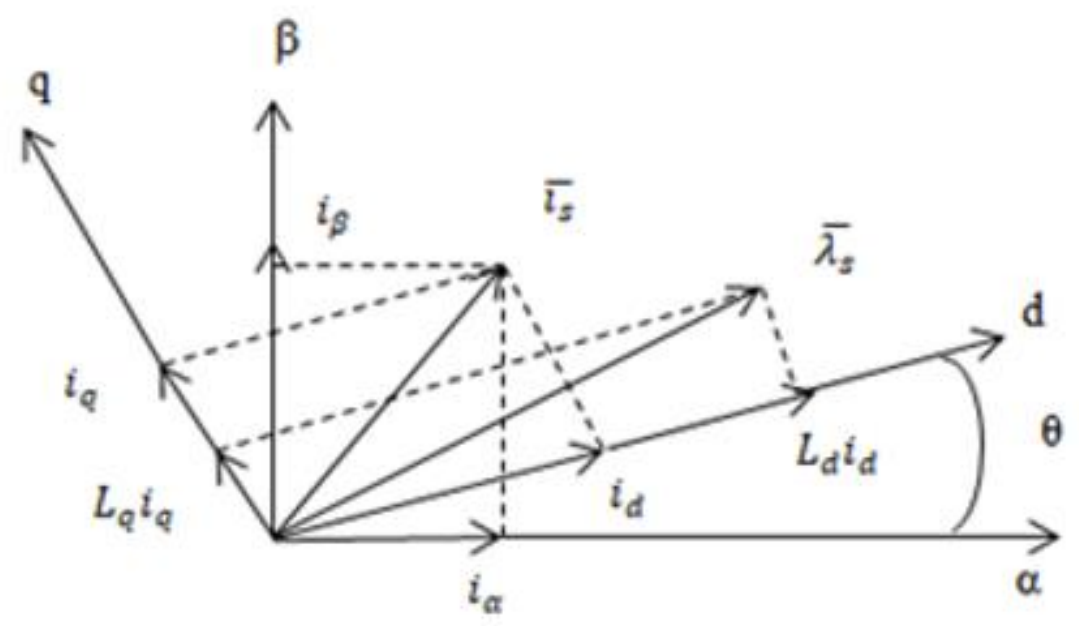

Fig 8. Rotor-oriented control of SynRM.

\section{MATLAB/SIMULINK Implementation}


The voltage, flux, and torque equations, and the transformation matrices built-in MATLAB, were used to simulate a five-phase SynRM model in [22]. The five-phase SVPWM is used to produce switching pulses for the IGBTs in the five-phase inverter. The overall control algorithm discussed previously with five-phase SynRM and five-phase current regulated SVPWM simulation is performed by MATLAB/SIMULINK program and described in Figure 9 [23]. The parameters listed in Table 1 are used to design and simulate the mathematical model of the concerned motor. Table 2 shows the PI parameters of the individual speed and current controllers.

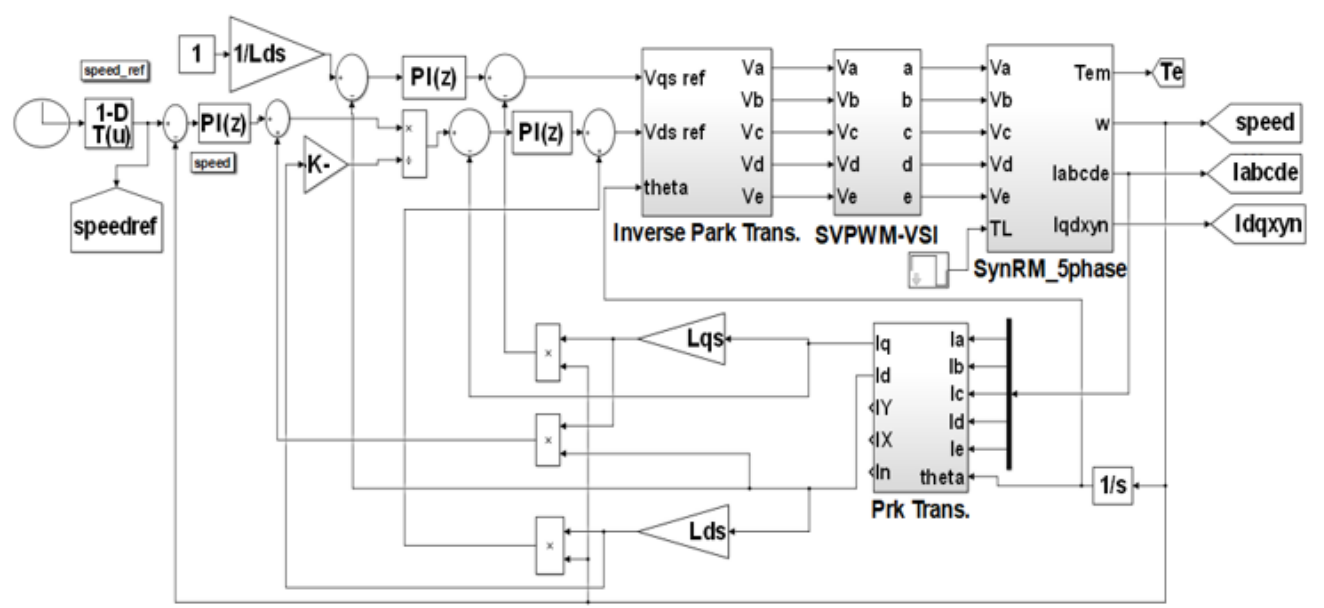

Fig 9. Field flux oriented control of five-phase SynRM simulation.

Table 1. Motor Parameters.

\begin{tabular}{ccc}
\hline Parameters & Description & Values \\
\hline$L_{d}$ & $\begin{array}{c}\text { inductance on d- } \\
\text { axis }\end{array}$ & $1.2 \mathrm{H}$ \\
& $\begin{array}{c}\text { inductance on q- } \\
\text { axis }\end{array}$ & $0.1 \mathrm{H}$ \\
& $\begin{array}{c}\text { Voltage in Rated } \\
\text { State }\end{array}$ & $415 \mathrm{~V}$ \\
$V_{\text {rated }}$ & $\begin{array}{c}\text { Stator resistance } \\
R_{S}\end{array}$ & 4 \\
$\mathrm{~J}$ & Inertia & 0.125 \\
& Kg.m2 \\
$\mathrm{B}$ & Damping & 0.009 \\
$\mathrm{P}$ & Number of Poles & 4 \\
\hline
\end{tabular}




\begin{tabular}{ccc}
\hline$N_{\text {rated }}$ & Rated speed & 1500 r.p.m \\
$\mathrm{F}$ & Frequency & $50 \mathrm{~Hz}$ \\
$f_{s}$ & $\begin{array}{l}\text { Switching } \\
\text { frequency }\end{array}$ & $5 \mathrm{kHz}$ \\
\hline
\end{tabular}

Table 2. PI controllers' parameters.

\begin{tabular}{ccc}
\hline Parameters & \multicolumn{2}{c}{ Controller } \\
\cline { 2 - 3 } & Speed & Current \\
\hline$K_{P}$ & 0.52 & 0.1 \\
$K_{I}$ & 1.5 & 2.3 \\
\hline
\end{tabular}

\section{Simulation Results}

\section{A. MOTOR SPEED IN R.P.M}

The five-phase SynRM's dynamic output is exanimated for operation under indirect rotor-field directed control. Acceleration transient starts from standstill to the rated speed 1500 r.p.m at $\mathrm{t}=$ $0.3 \mathrm{sec}$. till $\mathrm{t}=0.6 \mathrm{sec}$. After that speed is reversed till $\mathrm{t}=1 \mathrm{sec}$. at -1500 r.p.m as shown in Fig 10 . It is worth noting that the actual speed in Fig 11 closely matches the reference speed, and the speed with reference speed is illustrated together in Fig 12. Rotor position in (rad), which is the integration of the speed is illustrated in Fig 13, and its variation concerning the speed variation is apparent.

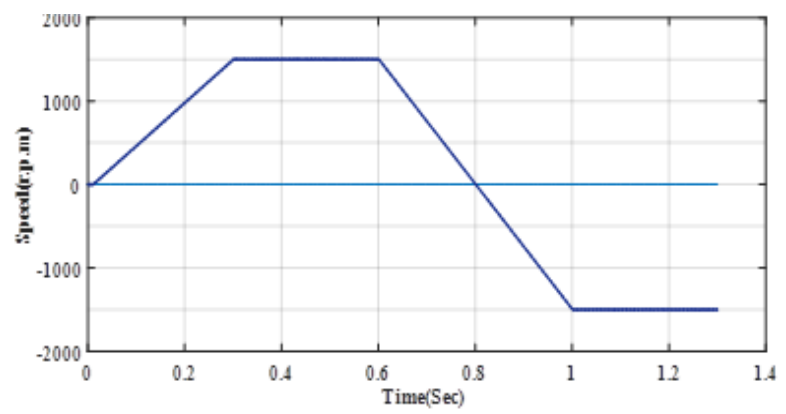

Fig 10. Motor speed in (r.p.m). 


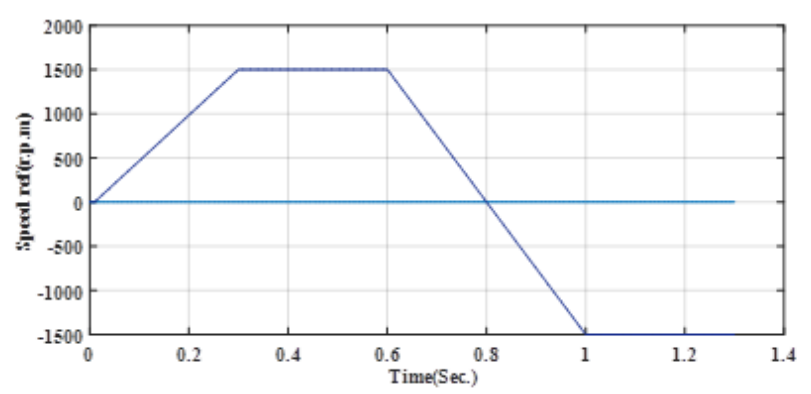

Fig 11. Reference speed (r.p.m).

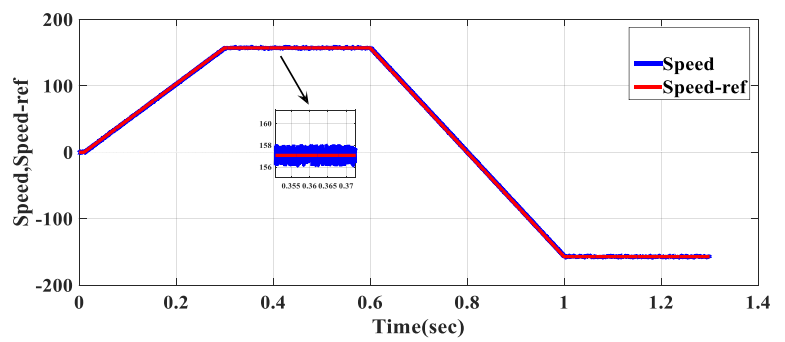

Fig 12. Speed with reference speed.

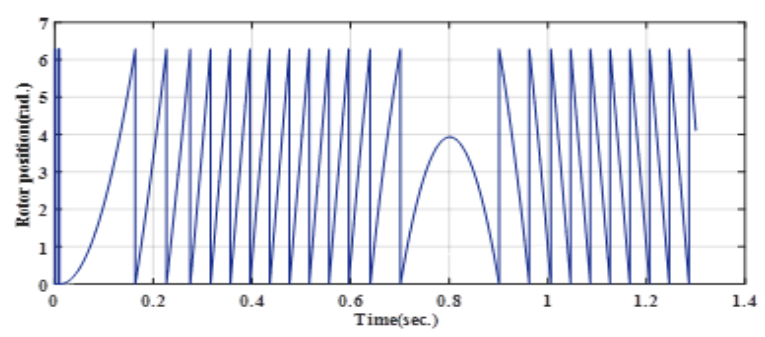

Fig 13. Rotor position (rad).

\section{B. ELECTROMAGNETIC TORQUE AND LOAD TORQUE}

Fig 14 displays load torque which is varied from zero to $20 \mathrm{~N} . \mathrm{m}$ at $\mathrm{t}=0.01 \mathrm{sec}$. till $\mathrm{t}=0.7 \mathrm{sec}$, then drop to $-20 \mathrm{~N} . \mathrm{m}$ at $\mathrm{t}=1 \mathrm{sec}$. The developed torque is assumed to be started from the rated torque 40 N.m and stabilized at the steady-state torque 20 N.m in the positive operation of the motor, and -20 N.m in the negative operation of the motor, as depicted in Fig 15. 




Fig 14. Load Torque (N.m).

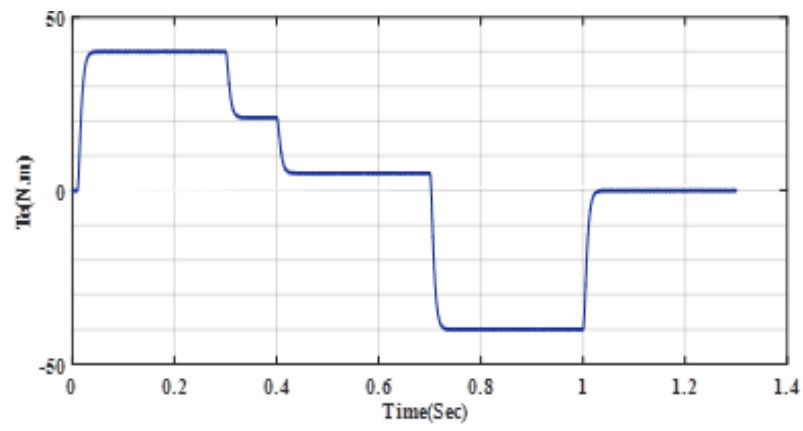

Fig 15. Electromagnetic Torque (N.m).

\section{Direct Quadrature Axis Currents}

According to the control strategy, the d-axis current is kept constant at $5 \mathrm{~A}$ to obtain the machine's rated voltage as in Fig 16, while the q-axis current is varied with the developed torque as shown in Fig 17.

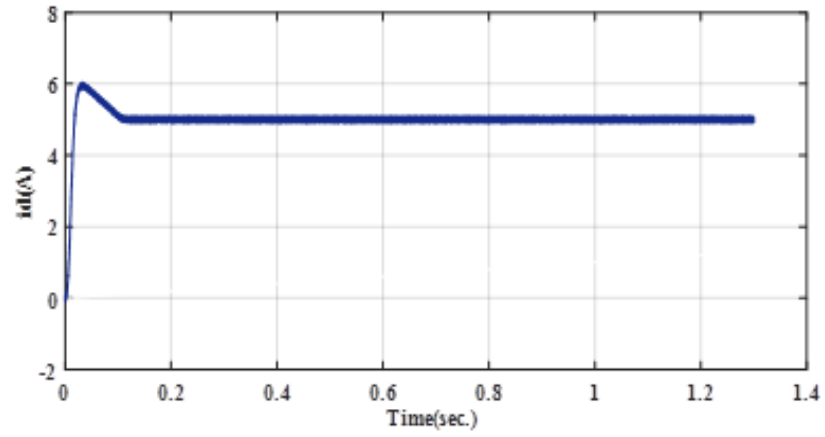

Fig 16. Direct-axis current (A). 


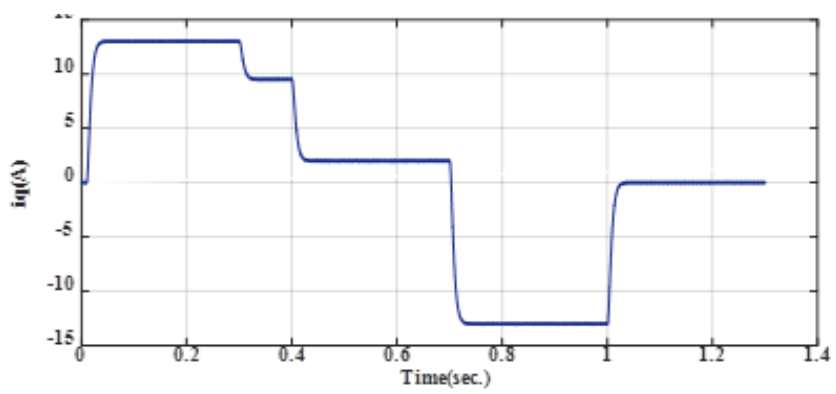

Fig 17. Quadrature-axis current (A).

\section{Actual Five-Phase Currents}

Fig 18 shows the real five-phase currents $i_{a b c d e}$ obtained from the machine. These currents are achieved using inverse park transformation. When the motor alters its speed from 1500 r.p.m to -1500 r.p.m, these currents are inversed due to speed changing.

\section{E. Stator Phase Voltages and Phase to Phase Voltage}

The phase $v_{a b c d e}$ terminal voltages of the stator are seen in Fig 19, while the line-to-line voltage waveform is shown in Fig 20.

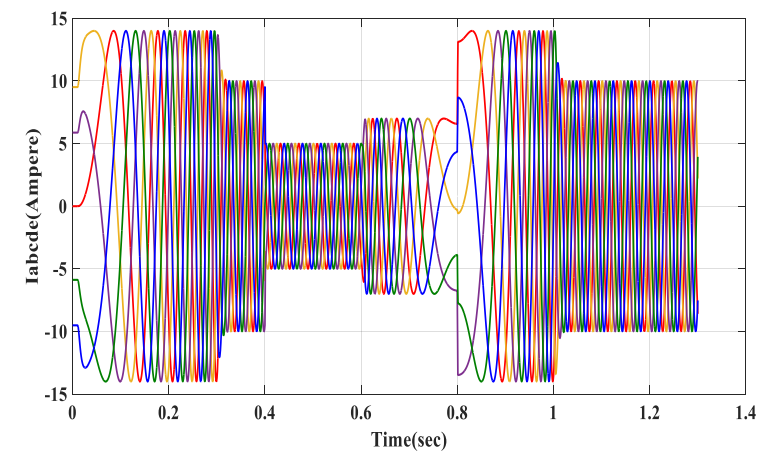

Fig 18. Stator phase currents $i_{a b c d e}$ (A).

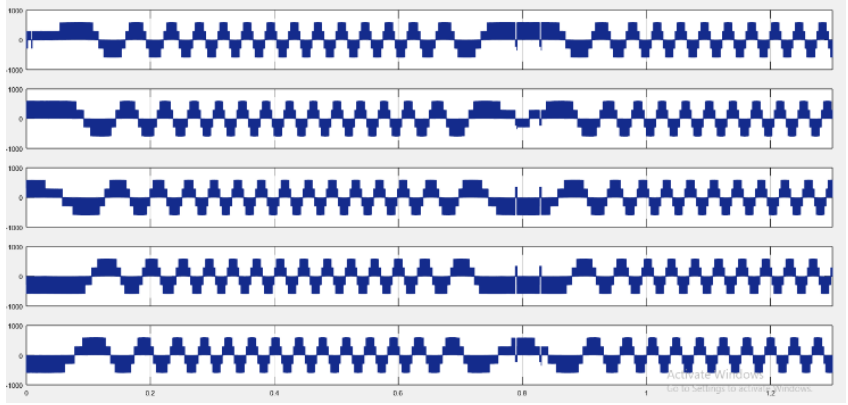

Fig 19. Phase voltages $v_{a b c d e}$ (volt). 


\section{F. Stator Flux Linkage}

The variance of stator flux in all situations is depicted in Fig 21. The d-axis and q-axis fluxes changing show that the stator flux is revolving along a predetermined direction, and the indications were typical.

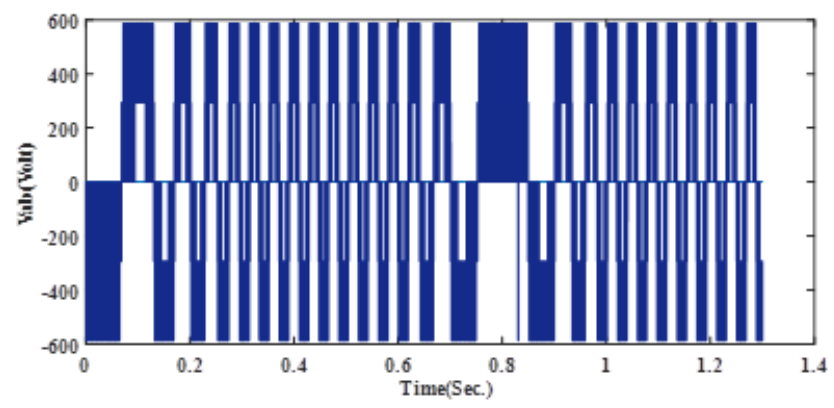

Fig 20. Line-line voltage $v_{a b}$ (volt).

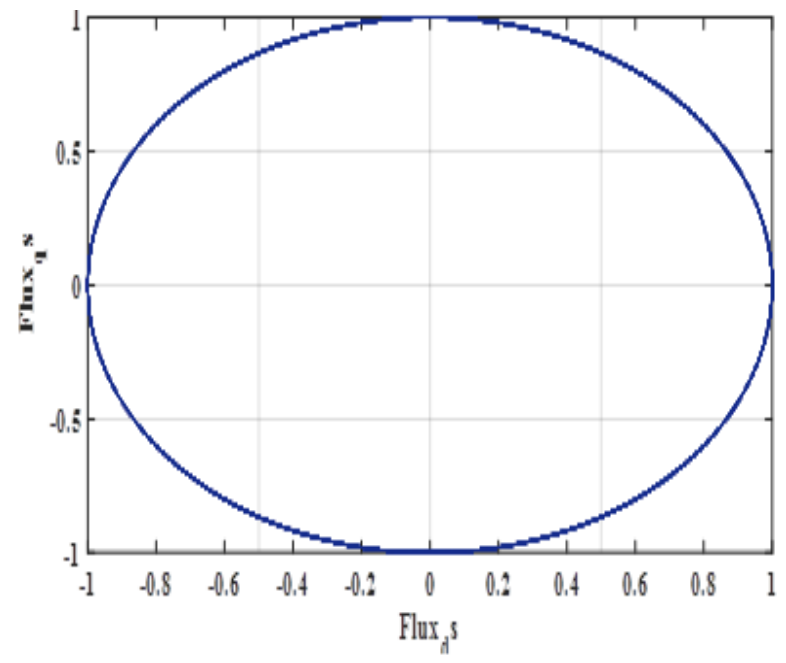

Fig 21. Stator Flux linkages.

\section{Conclusions}

The simulation models of a five-phase SynRM driven by a five-phase voltage source PWM inverter were recognized in this paper. According to a study in the field of multiphase machines, it is necessary to develop machines with a greater number of phases. Multiphase machines have many pros, such as high trustworthiness when the machines run incessantly even if one of its several phases is open or short-circuited without deficiency in performance as well as a smaller amount of current per phase which is a favorable characteristic exclusively in electric vehicles and analogous applications. This model is being used to create the indirect rotor flux field guided vector control of five-phase SynRM after it is used to implement a fivephase current-controlled SVPWM inverter, with outer speed closed-loop control and inner 
currents loop control by using PI controllers. Thus, all simulation results approve the developed model legitimacy at all the transient, dynamics, and steady-state responses. Furthermore, the previous results verify that the proposed control system assurances stable and robust responses under a varied range of operating conditions. Consequently, it can be utilized for control applications with high-performance motion.

\section{References}

[1] H. A. Toliyat, S. P. Waikar, and T. A. Lipo, "Analysis and simulation of five-phase synchronous reluctance machines including the third harmonic of air gap MMF," IEEE Transactions on Industry Applications, vol. 34, no. 2, pp. 332-339, 1998.

[2] R. Shi, H. A. Toliyat, and A. El-Antably, "A DSP- based direct torque control of five-phase synchronous reluctance motor drive," APEC 2001. Sixteenth Annual IEEE Applied Power Electronics Conference and Exposition, pp. 1077-1082, 2001.

[3] R. Shi, H. A. Toliyat, and A. El-Antably, "Field oriented control of five-phase synchronous reluctance motor drive with flexible $3^{\text {rd }}$ harmonic current injection for high specific torque," IEEE Industry Applications Conference. 36th IAS Annual Meeting, Chicago, IL, pp. 2097-2103, 2001.

[4] S. M. Ismaeel, S. M. Allam, E. M. Rasheed, "Current vector control techniques of five phase synchronous reluctance motor," International Middle East Power Systems Conference (MEPCON),Cairo, Egypt, pp. 1180-1185, 2019.

[5] R. Shi and H. A. Toliyat, "Vector control of five-phase synchronous reluctance motor with space vector pulse width modulation (SVPWM) for minimum switching losses," APEC. Seventeenth Annual IEEE Applied Power Electronics Conference and Exposition, Dallas, TX, USA, vol. 1, pp. 57-63, 2002.

[6] S. J. Mun, Y. H. Cho, \& J. H. Lee, "Optimum design of synchronous reluctance motors based on torque/volume using finite-element method and sequential unconstrained minimization technique," IEEE Transactions on Magnetics, vol. 44, no. 11, pp. 4143-4146, 2008.

[7] T. J. E. Miller, Brushless Permanent-Magnet and reluctance motor drives, $2^{\text {nd }}$ ed, Oxford university press, New York, 1989. Chapter three, Permanent-magnet materials and circuits; pp. 34-50.

[8] H. A. Toliyat, R. Shi, and H. Xu, "A DSP-based vector control of five phase synchronous reluctance motor," IEEE Industry Applications Conference, Thirty-Fifth IAS Annual Meeting and World Conference on Industrial Applications of Electrical Energy, Rome, Italy, vol. 3, no. 3, pp. 1759-1765, 2000.

[9] B. Bilgin, J. w. Jiang and A. Emadi, Switched Reluctance Motor Drives :fundamentals to applications, $1^{\text {st }}$ ed, CRC Press, Taylor and francis group, 2019. Chapter two, Electromagnetic principle of switch reluctance motor; pp.35-90.

[10] Q. chen, Y. Yan, G. Xu and M. Xu, "Principle of Torque Ripple Reduction in Synchronous Reluctance Motors With Shifted Asymmetrical Poles," IEEE Journal of Emerging and Selected Topics in Power Electronics, vol. 8, no. 3, 2020.

[11] Q. Chen, X. Shi, G. Xu and W. Zhao, "Torque calculation of five-phase synchronous reluctance motors with shifted-asymmetrical-salient-poles under saturation condition," CES Transactions on Electrical Machines and Systems, IEEE, vol. 4, no. 2, 2020.

[12] A. Iqbal, "Dynamic performance of a vector-controlled five-phase synchronous reluctance motor drive: an experimental investigation, " IET Electric Power Applications, vol. 2, no. 2, pp. 298-305, 2008. 
[13] A. Iqbal, E. Levi, M. Jones and Mohibullah, "Simulation studies of current regulated PWM VSI fed multi-phase AC machine drives, " Proceedings Student Conference on Research and Development, Putrajaya, Malaysia, SCORED, pp. 390-394, 2003.

[14] H. A. Toliyat, L. Xu and T. A. Lipo, "A five phase reluctance motor, with high specific torque, " IEEE Transactions on Industry Applications, vol. 28, no. 3, pp. 659-665, 1992.

[15] A. K. M. Arafat \& S. Choi, "Optimal phase advance under fault-tolerant control of a five-phase permanent magnet assisted synchronous reluctance motor," IEEE Transactions on Industrial Electronics, vol. 65, no. 4, pp. 2915-2924, 2017.

[16] S. S. R. Bonthu, S. Choi, J. Baek, "Comparisons of three-phase and five-phase permanent magnet assisted synchronous reluctance motor, " IET Electric Power Applications , vol. 10, no. 5, pp. 5- 2016.

[17] V. Bilyi, D. Bilyi, O. Moros, G. Dajaku and D. Gerling, "Synchronous reluctance Machine with multiphase stator cage winding, " 20th International Conference on Electrical Machines and Systems (ICEMS), Sydney, NSW, Australia, 2017.

[18] H. Abu-Rub, A. Iqbal \& J. Guzinski, High performance control of AC drives with MATLAB/Simulink models, $1^{\text {st }}$ ed., John Wiley \& Sons, 2012.

[19] K.Chen and Y.Xie, "Reducing Harmonic Distortion in Five-Phase VSI Using Space Vector Based Optimal Hybrid PWM, " IEEE Transactions on power electronics", vol. 32,no. 3, pp. 2098-2113, 2017.

[20] D.Raja and G.Ravi, "Design and implementation of Five-Phase Inverter With SVPWM Switching Technique for Induction Motor Drive," IEEE Fifth International Conference on Science Technology Engineering and Mathematics(ICONSTEM), vol. 1, no. 1, pp. 332-337. 2019.

[21] S.C.Rangari,H.M.Suryawanshi and B.Saha "Implementation of Large and Medium Vectors for FivePhase Voltage Source Inverter'IEEE International Conference on Intelligent Computing and Control Systems(ICICCS), pp.751-756,2017.

[22 ]N. A. Ameen, A. K. Abdulabbas and H. J. Nekad, "Modelling and Simulation of Five-Phase synchronous Reluctance Motor Fed by Five-Phase Inverter", Iraqi Journal for Electrical and Electronic Engineering(IJEEE), vol.17, no.1, pp. 1-8, 2021.

[23] J.Kacprzyk, Advanced Control of Electrical Drives and Power electronic Converters, $1^{\text {st }}$ ed, vol.75, Springer, Press 2017. Chapter one, Sensorless control of polyphase induction machine; pp.3-26. 